\title{
Toxic effect of polycyclic aromatic hydrocarbon metabolites on fish bone metabolism
}

\author{
K. Hayakawa ${ }^{1}$, N. Suzuki ${ }^{2}$, K. Kitamura ${ }^{3}$, K. Bekki ${ }^{1}$, J. Nakano ${ }^{1}$,

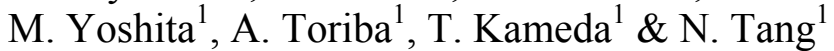 \\ ${ }^{1}$ Institute of Medical, Pharmaceutical and Health Sciences, \\ Kanazawa University, Japan \\ ${ }^{2}$ Noto Marine Laboratory, Kanazawa University, Japan \\ ${ }^{3}$ Division of Health Sciences, Graduate School of Medical Science, \\ Kanazawa University, Japan
}

\begin{abstract}
Marine water is contaminated with polycyclic aromatic hydrocarbons (PAHs) from rivers and the atmosphere. Oil spilled from tankers or petroleum factories also causes marine pollution with PAHs. It is well known that PAHs, such as benzo $[a]$ pyrene, show carcinogenicity and/or mutagenicity. In developing teleost fish, furthermore, it has been reported that spinal deformity was induced in Pacific herring and pink salmon by PAHs, although the detail mechanism of toxicity in teleosts is not elucidated yet. As a toxic pathway of PAHs in animals, the metabolic activation of PAHs in the presence of P450 is considered. In teleosts, as well as in mammals, it has been reported that PAHs are converted into monohydroxylated polycyclic aromatic hydrocarbons (OHPAHs) by an enzyme: cytochrome P4501A1. Thus, OHPAH might have a toxic effect in teleosts. In the present study, we examined the estrogenic activity of OHPAHs using the yeast-two hybrid assay system with human estrogen receptor (ER) $\alpha$. As a result, we detected estrogenic activity in 4-hydroxybenz $[a]$ anthracene (4$\mathrm{OHBaA}$ ). Then, the direct effect of 4-OHBaA on osteoclasts and osteoblasts in teleosts was examined using the assay system with fish scales, which contain osteoclasts, osteoblasts, and the bone matrix of two layers (bony layer: a thin, well-calcified external layer; a fibrillary layer: a thick, partially calcified layer). When the scales of goldfish and wrasse were incubated with 4-OHBaA, which
\end{abstract}


showed agonistic activity in the yeast-two hybrid assay system described above, the suppressing effect was observed for both osteoclasts and osteoblasts. The osteoclastic and osteoblastic activities did not change with 1-hydroxypyrene, which has no binding activity to human ER $\alpha$. Thus, we conclude that PAH metabolites have a toxic effect on fish bone metabolism and that careful attention should be given to aquatic PAH contamination.

Keyword: polycyclic aromatic hydrocarbons, oil spill, yeast-two hybrid assay, osteoclasts, osteoblasts, teleost scale.

\section{Introduction}

Polycyclic aromatic hydrocarbons (PAHs) are ubiquitous environmental pollutants. They are formed through incomplete combustion of fossil fuel, wood and other organic materials including automobile exhaust, domestic heating and industrial processes.

Storm water runoff and atmospheric deposition of PAHs are now the largest sources of aquatic PAH contamination [1,2]. Furthermore, an oil spill from an oil tanker, such as the Exxon Valdez and Nakhodka, directly induces contamination by PAHs in a marine environment [3-5]. In the Nakhodka Cheavy oil, $210 \mu \mathrm{g} / \mathrm{g}$ of benz $[a]$ anthracene having four aromatic rings was detected [5]. In developing teleosts, it has been reported that spinal deformity was induced in Pacific herring and pink salmon by PAHs [6, 7] although the detail mechanism of toxicity in teleosts has not elucidated yet. As a toxic pathway of PAHs in animals, the metabolic activation of PAHs in the presence of P450 is considered. In teleost fish, as well as in mammals, it is known that PAHs are converted into monohydroxylated polycyclic aromatic hydrocarbons (OHPAHs) by the enzyme cytochrome P4501A1 [7-10]. Thus, PAH metabolites such as OHPAH might have a toxic in teleosts.

In the present study, we examined estrogenic activity of OHPAHs using the yeast-two hybrid assay system with human estrogen receptor (ER) $\alpha$. Then, the direct effect of 4-hydroxybenz $[a]$ anthracene $(4-\mathrm{OHBaA})$ on osteoclasts and osteoblasts in teleosts was examined using the assay system with fish scale, which contains osteoclasts, osteoblasts, and the bone matrix of two layers (bony layer: a thin, well-calcified external layer; a fibrillary layer: a thick, partially calcified layer) $[11,12]$. Using the scale assay, furthermore, we compared the results with those of 1-hydroxypyrene (1-OHPy), which had no binding activity to $\mathrm{ER} \alpha$ as a negative control.

\section{Methods}

\subsection{Chemicals}

Chemical structures of OHPAHs, quinoid PAHs (PAHQs) PAH ketones (PAHKs) and tested in this report are shown in Figs. 1 and 2. These chemicals were purchased from Kanto Chemical (Tokyo, Japan), Aldrich (Milwaukee, WI, 

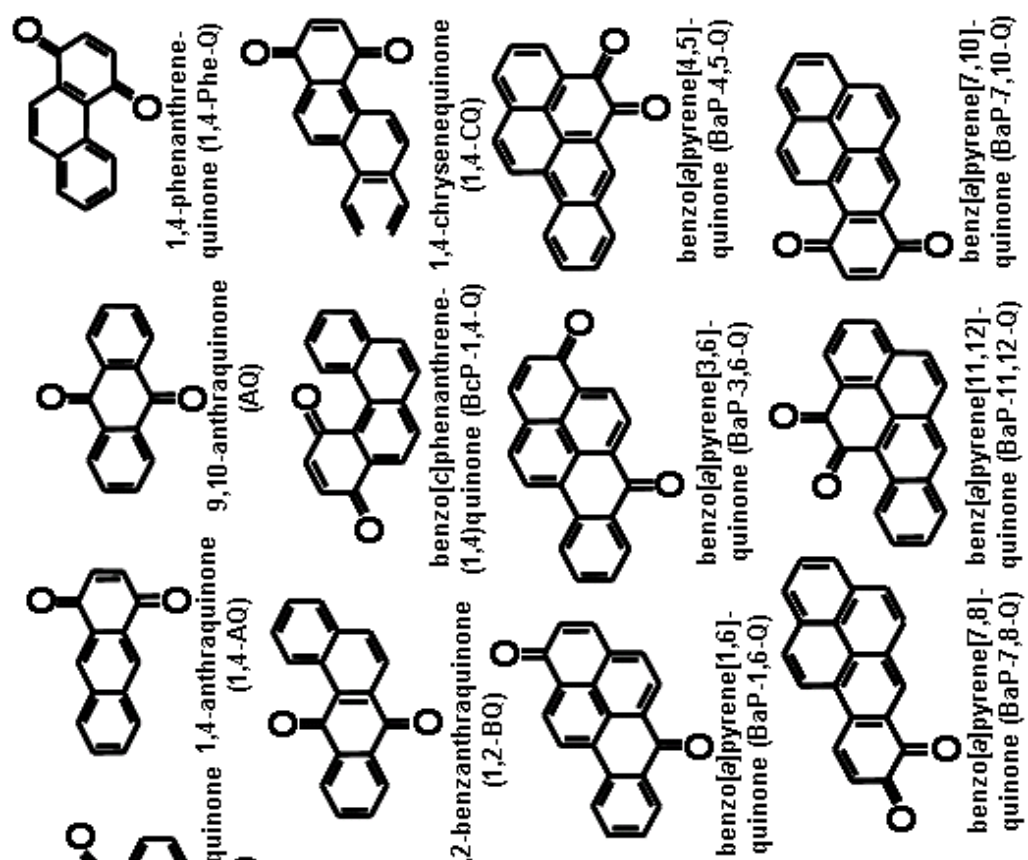


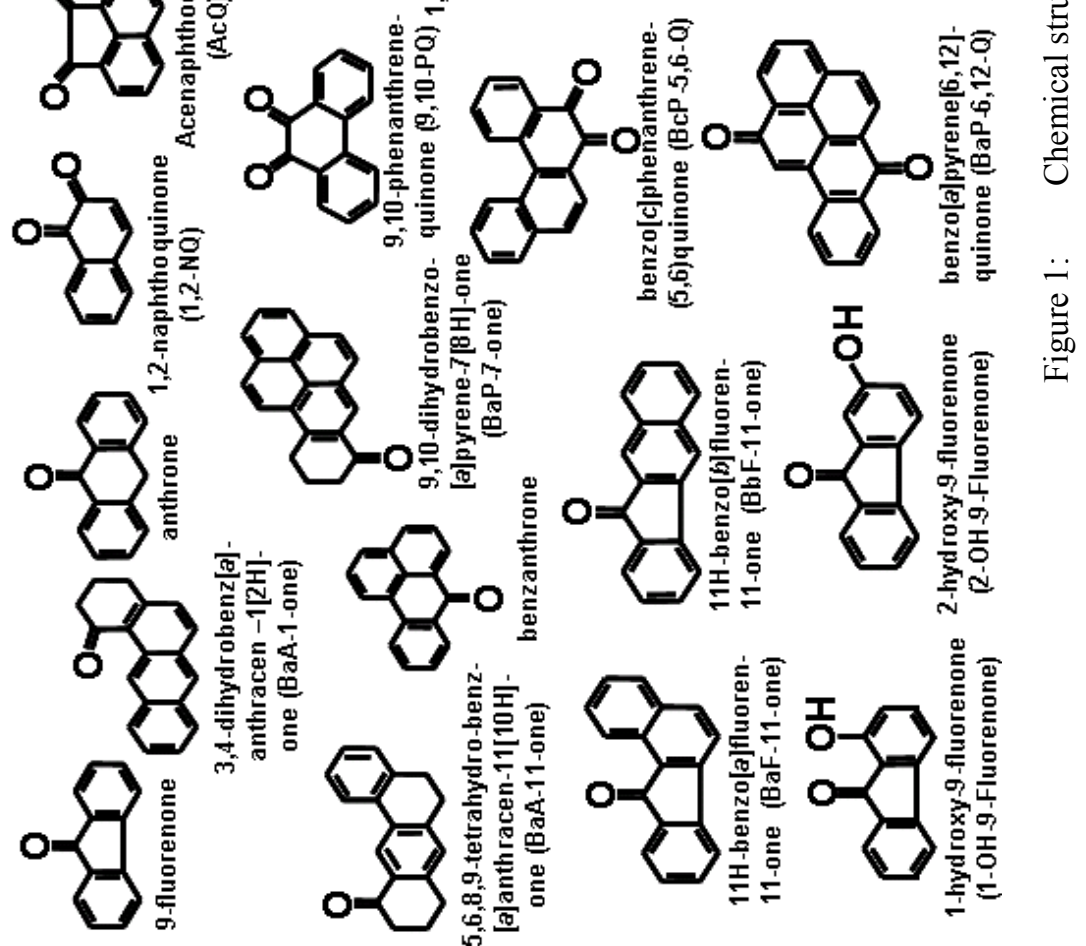

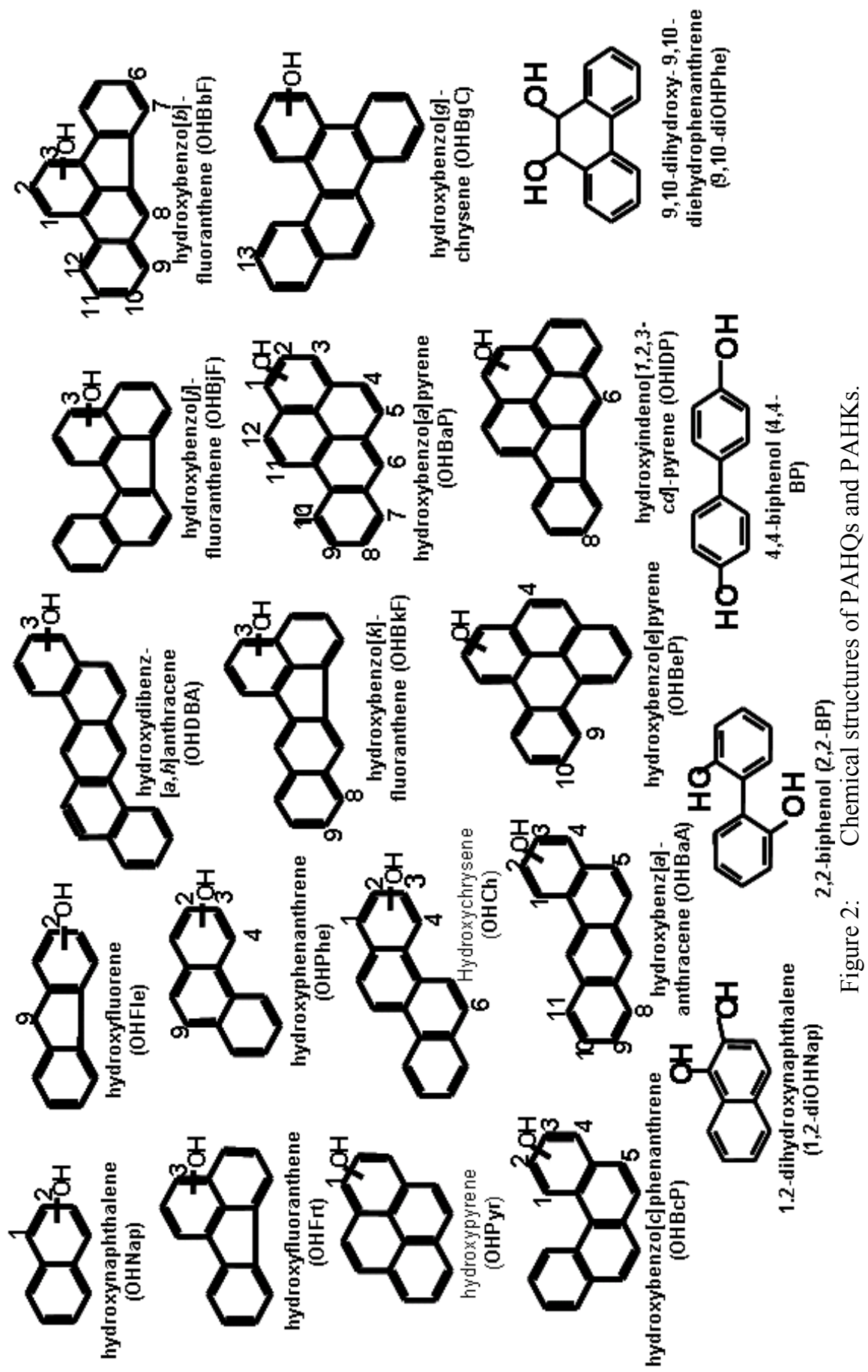

WIT Transactions on Ecology and the Environment, Vol 135, (C) 2010 WIT Press 
USA), Chiron AS (Trondheim, Norway), and NCI Chemical Carcinogen Repository (Kansas City, MO, USA). Test compounds were dissolved in ethanol and stored at $-20^{\circ} \mathrm{C}$ until use. All other chemicals were of the highest quality available from commercial sources.

\subsection{Assay of estrogenic activities}

Yeast cells expressing human ER $\alpha$ were prepared according to the previous report [13]. Estrogenic activity of OHPAHs was evaluated by the yeast twohybrid assay method using the above yeast cells as described [14]. To examine the agonistic activity of OHPAHs, the yeast cells were grown overnight at $27^{\circ} \mathrm{C}$ with shaking in synthetic defined medium free from tryptophan and leucine, and treated with each test compound in the concentration range from $1 \times 10^{-9} \mathrm{M}$ to 1 $\times 10^{-6} \mathrm{M}$ at $27^{\circ} \mathrm{C}$ for $4 \mathrm{hrs}$. After the incubation, the treated cells were collected and enzymatically digested with $1 \mathrm{mg} / \mathrm{ml}$ Zymolyase $20 \mathrm{~T}$ at $37^{\circ} \mathrm{C}$ for $20 \mathrm{~min}$. 2Nitrophenyl- $\beta$-D-galactoside (ONPG) was added to the lysate to a final concentration of $4 \mathrm{mg} / \mathrm{ml}$. After incubation at $27^{\circ} \mathrm{C}$ for $20 \mathrm{~min}$, the reaction was stopped by the addition of $1 \mathrm{M} \mathrm{Na}_{2} \mathrm{CO}_{3}$. The yeast debris was removed by centrifugation and $\beta$-galactosidase activity was assayed by measuring the absorbance of supernatant at $415 \mathrm{~nm}$. Three independent experiments were run, and the mean values of the three were shown in this report. Relative effective potency of estrogenic activity $\left(\mathrm{REP}_{\mathrm{E}}\right)$ was calculated as the value of the relative concentration of the test compound that gave the same activity of $17 \beta$-estradiol $\left(\mathrm{E}_{2}\right)$.

\subsection{Animals}

A previous study [15] indicated that sensitivity to calcemic hormones was higher in mature female than in mature male teleosts. Therefore, female goldfish (Carassius auratus) were purchased from a commercial source (Higashikawa Fish Farm, Yamato-koriyama, Japan), and their scales were used in an in vitro assay. As a marine teleost, female wrasse (Pseudolabrus sieboldi) caught in Tsukumo Bay of Noto Peninsula were used. These fish were kept under normal conditions until the start of experiments.

All experimental procedures were conducted in accordance with the Guide for the Care and Use of Laboratory Animals of Kanazawa University.

\subsection{Effects of OHPAHs and $E_{2}$ on osteoclastic activity in cultured scales of goldfish and wrasse}

The 4-OHBaA and 1-OHPy (NCI Chemical Carcinogen Repository), and $\mathrm{E}_{2}$ (water-soluble type, Sigma-Aldrich, Inc., MO, USA) were purchased and used in the present study.

A $1 \%$ penicillin-streptomycin mixture (ICN Biomedicals, Inc., OH, USA) was added to Eagle's modified minimum essential medium (MEM; ICN Biomedicals, Inc.). HEPES (Research Organics, Inc., OH, USA) (20 mM) was added to MEM and adjusted to $\mathrm{pH}$ 7.0. After filtration, MEM was used in this experiment. Scales were collected from goldfish and wrasse under anesthesia 
with ethyl 3-aminobenzoate, methanesulfonic acid salt (Sigma-Aldrich, Inc.). The scales were cut into halves. One half of a piece was then placed into a well of a 24-well microplate in MEM (1 ml) supplemented with OHPAHs or $\mathrm{E}_{2}\left(10^{-7}\right.$, $10^{-6}$, and $\left.10^{-5} \mathrm{M}\right)$. The other half was also placed into a well of a 24 -well microplate in an $\mathrm{OHPAH} / \mathrm{E}_{2}$-free medium as a control. Eight scales were used for each dose. These scales were incubated for $6 \mathrm{hrs}$ at $15^{\circ} \mathrm{C}$. After incubation, each incubated scale was washed with saline and transferred to its own well in a 96-well microplate. An aliquot of $100 \mu \mathrm{l}$ of $20 \mathrm{mM}$ tartrate in a $0.1 \mathrm{M}$ sodium acetate buffer ( $\mathrm{pH}$ 5.3) was added to each well. This microplate was frozen at $-85^{\circ} \mathrm{C}$ immediately and kept at $-20^{\circ} \mathrm{C}$ until analysis.

To analyze the tartrate-resistant acid phosphatase (TRAP) activity, an aliquot of $100 \mu \mathrm{l}$ of $20 \mathrm{mM}$ para-nitrophenyl-phosphate and $20 \mathrm{mM}$ tartrate in a $0.1 \mathrm{M}$ sodium acetate buffer ( $\mathrm{pH}$ 5.3) was added to each well of a melted solution in the microplate. This plate was incubated at $20^{\circ} \mathrm{C}$ for $30 \mathrm{~min}$ while being shaken. After incubation, the reaction was stopped by adding $50 \mu$ of a $3 \mathrm{~N} \mathrm{NaOH}-20$ $\mathrm{mM}$ EDTA solution. A colored solution of $150 \mu \mathrm{l}$ was transferred to a new plate, and the absorbance was measured at $405 \mathrm{~nm}$. The absorbance was converted into the amount of produced para-nitrophenol (pNP) using a standard curve for pNP. Detail methods were described in Suzuki et al. [11].

\subsection{Effects of OHPAHs and $E_{2}$ on osteoblastic activity in cultured scales of goldfish and wrasse}

Goldfish and wrasse were anesthetized with ethyl 3-aminobenzoate, methanesulfonic acid salt (Sigma-Aldrich, Inc.), and scales were collected from them. The scales were cut into halves. One half of a piece was then placed into a well of a 24-well microplate in MEM (1 ml) supplemented with OHPAHs or $\mathrm{E}_{2}$ $\left(10^{-7}, 10^{-6}\right.$, and $\left.10^{-5} \mathrm{M}\right)$. The other half was also placed into a well of a 24 -well microplate as a control. Eight scales were used for each dose. These scales were incubated for $6 \mathrm{hrs}$ at $15^{\circ} \mathrm{C}$. After incubation, each incubated scale was washed with saline and transferred to its own well in a 96-well microplate. An aliquot of $100 \mu \mathrm{l}$ of an alkaline buffer $(100 \mathrm{mM}$ Tris- $\mathrm{HCl}, \mathrm{pH} 9.5 ; 1 \mathrm{mM} \mathrm{MgCl} ; 2 ; 0.1 \mathrm{mM}$ $\mathrm{ZnCl}_{2}$ ) was added to each well. This microplate was frozen at $-85^{\circ} \mathrm{C}$ immediately and kept at $-20^{\circ} \mathrm{C}$ until analysis.

The ALP activities were measured in the same manner as for the measurement of TRAP activity.

\subsection{Statistical analysis}

The statistical significance was assessed by the student's $t$-test. The selected significance level was $P<0.05$.

\section{Results}

\subsection{Estrogenic activity}

The results are indicated in Figure 3. A significant increase of $\beta$-galactosidase activity $\left(\mathrm{REP}_{\mathrm{E}}>1 \times 10^{-3}\right)$ was observed for 3-, 4- and 10-OHBaAs and 
2-hydroxychrysene (2-OHCh). These were all 4-ring OHPAHs. Among them, 4-OHBaA exhibited the strongest estrogenic activity $\left(\mathrm{REP}_{\mathrm{E}}=7.5 \times 10^{-3}\right)$. 2-hydroxyfluorene (2-OHFle), 2-hydroxuphenanthrene (2-OHPh) (3-ring), 3-hydroxyfluoranthene (3-OHFrt), 1-OHPy, 1-OHCh, 3-hydroxybenzo $[k]$ fluoranthene, 12-hydroxybenzo[ $b]$ fluoranthene (4-ring) and 4-hydroxybenzo[e]pyrene (5-ring) were also active $\left(1 \times 10^{-3}>\mathrm{REP}_{\mathrm{E}} \geq 1 \times 10^{-4}\right)$. The estrogenic activities of the other OHPAHs, PAHQs and PAHKs were much weaker or undetectable.

\subsection{Effects of OHPAHs and $E_{2}$ on osteoclastic activity in cultured scales of goldfish and wrasse}

The results are summarized in Table 1. In goldfish, the TRAP activity of the scales was significantly lowered by 4-OHBaA treatment at $6 \mathrm{hrs}$ of incubation $\left(10^{-7}\right.$ and $\left.10^{-6} \mathrm{M}, P<0.05,10^{-5} \mathrm{M}, P<0.01\right)$, although the TRAP activity did not change from that of the control with $1-\mathrm{OHPy} . \mathrm{E}_{2}$ significantly increased the TRAP activity at $6 \mathrm{hrs}\left(10^{-6}\right.$ and $\left.10^{-5} \mathrm{M}, P<0.05\right)$.

In the scales of wrasse after 4-OHBaA $\left(10^{-7}\right.$ to $\left.10^{-5} \mathrm{M}\right)$ treatment, the TRAP activity also decreased at $6 \mathrm{hrs}\left(10^{-6} \mathrm{M}, P<0.05,10^{-5} \mathrm{M}, P<0.01\right)$. There was no change in the TRAP activity in 1-OHPy-treated scales. In wrasse as well as goldfish, a significant difference $\left(10^{-5} \mathrm{M}, P<0.01\right)$ was obtained between $\mathrm{E}_{2}$ treated scales and control scales.

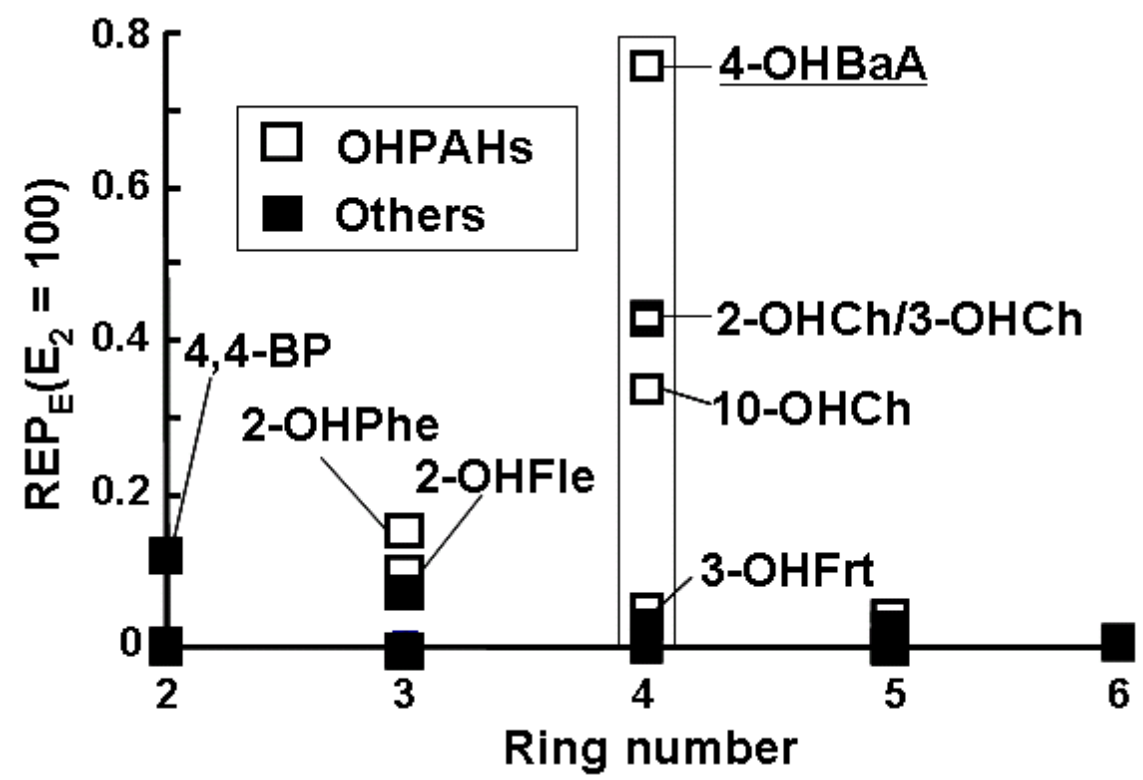

Figure 3: Relationship between the number of rings of OHPAHs and $\mathrm{REP}_{\mathrm{E}}$. $\mathrm{REP}_{\mathrm{E}}$ indicates the relative effective potency of estrogenic activity. 
Table 1: The toxicity of 4-OHBaA in osteoclasts and osteoblasts of the scales.

\begin{tabular}{lll}
\hline Goldfish (Fresh water teleost) & Osteoclasts & Osteoblasts \\
$\begin{array}{l}\text { 4-OHBaA } \\
\mathbf{E}_{2}\end{array}$ & $\begin{array}{l}\text { inhibition }\left(10^{-7} \mathrm{M}\right) \\
\text { activation }\left(10^{-6} \mathrm{M}\right) \\
\text { 1-OHPy }\end{array}$ & $\begin{array}{l}\text { inhibition }\left(10^{-5} \mathrm{M}\right) \\
\text { activation }\left(10^{-6} \mathrm{M}\right) \\
\text { no change }\end{array}$ \\
\hline Wrasse (Seawater teleost) & & \\
\hline 4-OHBaA & inhibition $\left(10^{-6} \mathrm{M}\right)$ & $\begin{array}{l}\text { inhibition }\left(10^{-5} \mathrm{M}\right) \\
\text { activation }\left(10^{-5} \mathrm{M}\right)\end{array}$ \\
$\mathbf{E}_{2}$ & $\begin{array}{l}\text { activation }\left(10^{-5} \mathrm{M}\right) \\
\text { 1-OHPy }\end{array}$ & $\begin{array}{l}\text { no change } \\
\text { no change }\end{array}$ \\
\hline
\end{tabular}

4-OHBaA: 4-hydroxybenz $[a]$ anthracene

$\mathrm{E}_{2}: 17 \beta$-estradiol

1-OHPy: 1-hydroxypyrene

\subsection{Effects of OHPAHs and $E_{2}$ on osteoblastic activity in cultured scales of goldfish and wrasse}

The results are summarized in Table 1. In goldfish scales, at $6 \mathrm{hrs}$ of incubation, the alkaline phosphatase (ALP) activity significantly decreased from the control values as a result of $4-\mathrm{OHBaA}$ treatment $\left(10^{-5} \mathrm{M}, P<0.01\right)$, while the ALP activity did not change with 1-OHPy treatment. $\mathrm{E}_{2}$ significantly increased the ALP activity at $6 \mathrm{hrs}$ of incubation $\left(10^{-6} \mathrm{M}, P<0.01 ; 10^{-5} \mathrm{M}, P<0.05\right)$.

Similar changes were induced by 4-OHBaA in the scales of wrasse. The ALP activity significantly decreased in 4-OHBaA-treated wrasse scales at $6 \mathrm{hrs} \mathrm{(4-}$ OHBaA: $10^{-5} \mathrm{M}, P<0.01$ ), although the ALP activity did not change from that of the control with 1-OHPy. In wrasse, a significant difference (at $6 \mathrm{hrs:} 10^{-5} \mathrm{M}$, $P<0.01)$ was obtained between $\mathrm{E}_{2}$-treated scales and control scales.

\section{Discussion}

The present study indicates that OHPAHs such as 4-OHBaA have an estrogenic activity using the yeast-two hybrid assay system with human ER $\alpha$. In rat cytosol as well, 2-hydroxybenz $[a]$ anthracene bound strongly to ER [16]. In the ER $\alpha$ reporter assay using a human breast cancer cell line (MCF-7), 3-OHBaA and 9OHBaA had binding activity to ER [8]. Our data are supported by these reports.

In both freshwater and seawater teleosts, 4-OHBaA suppressed both osteoclastic and osteoblastic activities in the scales using our in vitro assay system while $\mathrm{E}_{2}$ activated both osteoclastic and osteoblastic activities in the scales. $\mathrm{E}_{2}$-specific binding [17] was detected in the scales of rainbow trout. However, a different action from $\mathrm{E}_{2}$-treated scales was obtained in OHPAH- 
treated scales. In the case of bisphenol-A, which is bound to mammalian ER $\alpha$ [18], we previously reported that both osteoclastic and osteoblastic activities in the goldfish scales were significantly suppressed by bisphenol-A treatment [19]. In bony tissues including the scale of teleost, the $\beta$ subtype of the ER is mainly expressed [20], while $\alpha$ subtype of ER is expressed in mammals [8]. This may be one reason for the anti-estrogenic-like action in OHPAH. To examine the effects of OHPAHs on bone tissues of teleosts in detail, plans are underway to conduct micro-array analyses using the scales of zebrafish.

The present study indicated that the strength of the inhibition activity in goldfish was stronger than that in wrasse. In goldfish, even at $10^{-7} \mathrm{M}$ of 4$\mathrm{OHBaA}$, the osteoclastic activity was significantly inhibited. Exchange of calcium in the scales of freshwater teleosts may be faster than that in marine teleosts because they live in a low-calcium environment. In fact, the response of estrogen and calcitonin in the scales of freshwater teleosts was higher than that in those of marine teleosts $[15,21-23]$. In the case of the scales, therefore, OHPAHs were more toxic in freshwater teleosts.

An oil spill from an oil tanker such as the Exxon Valdez and Nakhodka directly induces contamination by PAHs in a marine environment. In the Cheavy oil of the Nakhodka, $210 \mu \mathrm{g} / \mathrm{g}$ of BaA having four aromatic rings was detected [5]. This concentration is similar to that in the present experiment. Immediately after the oil spill, the high level of PAHs influenced marine animals, including fish. For a long time (more than 14 years), the toxicity of PAHs originating from an oil spill affected many marine animals (for a review, see Peterson et al. [24]). These facts, in conjunction with the findings of our study, indicate that careful attention should be given to aquatic PAH contamination.

\section{Conclusion}

We found that OHPAHs such as 4-OHBaA had an estrogenic activity using the yeast-two hybrid assay system with human ER $\alpha$. This chemical suppressed both osteoclastic and osteoblastic activity in the scales of both freshwater and seawater teleosts. We believe that these phenomena are a cause of the disruption of the bone metabolism and the induction of spinal deformities in teleosts.

\section{Acknowledgements}

This study was supported in part by grants to K. Hayakawa (Grant-in-Aid for Scientific Research of ExTEND2005 and Global Environment Research Fund D091 by the Ministry of Environment in Japan; Grant-in-Aid for Scientific Research (B) No. 21390034 and for Exploratory Research No.21651018 by Japan Society for the Promotion of Science), to N. Suzuki (Kurita Water and Environment Foundation; Grant-in-Aid for Scientific Research (C) No. 21500404 by JSPS), and to K. Kitamura (Grant-in-Aid for Scientific Research (C) No. 21500681 by JSPS). 


\section{References}

[1] Lima, A. L. C., Eglinton, T. I. \& Reddy, C. M., High-resolution record of pyrogenic polycyclic aromatic hydrocarbon deposition during the 20th century. Environmental Science and Technology, 37, pp.53-61, 2003.

[2] Li, D. \& Daler, D., Ocean pollution from land-based sources: East China Sea, China. Ambio, 33, pp.107 113, 2004.

[3] Bue, B. G., Sharr, S. \& Seeb, J. E., Evidence of damage to pink salmon populations inhabiting Prince William Sound, Alaska, two generations after the Exxon Valdez oil spill. Transactions of the American Fisheries Society, 127, pp. 35-43, 1998.

[4] Heintz, R. A., Rice, S. D., Wertheimer, A. C., Bradshaw, R. F., Thrower, F. P., Joyce, J. E. \& Short, J. W., Delayed effects on growth and marine survival of pink salmon Oncorhynchus gorbuscha after exposure to crude oil during embryonic development. Marine Ecology Progress Series, 208, pp. 205-216, 2000.

[5] Hayakawa, K., Nomura, M., Nakagawa, T., Oguri, S., Kawanishi, T., Toriba, A., Kizu, R., Sakaguchi, T. \& Tamiya, E., Damage to and recovery of coastlines polluted with C-heavy oil spilled from the Nakhodka. Water Research, 40, pp. 981-989, 2006.

[6] Barron, M. G., Carls, M. G., Heintz, R. \& Rice, S. D., Evaluation of fish early life-stage toxicity models of chronic embryonic exposures to complex polycyclic aromatic hydrocarbon mixtures. Toxicological Science, 78, pp. 60-67, 2004.

[7] Billiard, S. M., Timme-Laragy, A. R., Wassenberg, D. M., Cockman, C. \& $\mathrm{Di}$, Giulio, R. T., The role of the aryl hydrocarbon receptor pathway in mediating synergistic developmental toxicity of polycyclic aromatic hydrocarbons to zebrafish. Toxicological Sciences, 92, pp. 526-536, 2006.

[8] Charles, G. D., Bartels, M. J., Zacharewski, T. R., Gollapudi, B. B., Freshour, N. L. \& Carney, E. W., Activity of benzo $[a]$ pyrene and its hydroxylated metabolites in an estrogen receptor- $\alpha$ reporter gene assay. Toxicological Sciences, 55, pp. 320-326, 2000.

[9] Jaruchotikamol, A., Jarukamjorn, K., Sirisangtrakul, W., Sakuma, T., Kawasaki, Y. \& Nemoto, N., Strong synergistic induction of CYP1A1 expression by andrographolide plus typical CYP1A inducers in mouse hepatocytes. Toxicology and Applied Pharmacology, 224, pp. 156-162, 2007.

[10] Mortensen, A. S. \& Arukwe, A., Targeted salmon gene array (SalArray): A toxicogenomic tool for gene expression profiling of interactions between estrogen and aryl hydrocarbon receptor signaling pathways. Chemical Research in Toxicology, 20, pp. 474-488, 2007.

[11] Suzuki, N., Kitamura, K., Nemoto, T., Shimizu, N., Wada, S., Kondo, T., Tabata, M. J., Sodeyama, F., Ijiri, K. \& Hattori, A., Effect of vibration on osteoblastic and osteoclastic activities: Analysis of bone metabolism using goldfish scale as a model for bone. Advance in Space Research, 40, pp. 1711-1721, 2007. 
[12] Suzuki, N., Somei, M., Seki, A., Reiter, R. J. \& Hattori, A., Novel bromomelatonin derivatives as potentially effective drugs to treat bone diseases. Journal of Pineal Research, 45, pp. 229 234, 2008.

[13] Morito, K., Hirose, T., Kinjo, J., Hirakawa, T., Okawa, M., Nohara, T., Ogawa, S., Muramatsu, M. \& Masamune, Y., Interaction of phytoestrogen with estrogen receptor $\alpha$ and $\beta$. Biol. Pharm. Bull., 24, pp. 351-356, 2001.

[14] Hirose, T., Morito, K., Kizu, R., Toriba, A., Hayakawa, K., Ogawa, S., Inoue, S., Muramatsu, M. \& Masamune, Y., Estrogenic/antiestrogenic activities of benzo[a]pyrene monohydroxy derivatives. Journal of Health Science, 47, pp. 552-558, 2001.

[15] Suzuki, N., Suzuki, T. \& Kurokawa, T., Suppression of osteoclastic activities by calcitonin in the scales of goldfish (freshwater teleost) and nibbler fish (seawater teleost). Peptides, 21, pp. 115-124, 2000.

[16] Ebright, R. H., Wong, J. R. \& Chen, L. B., Binding of 2hydroxybenzo $[a]$ pyrene to estrogen receptors in rat cytosol. Cancer Research, 46, pp. 2349-2351, 1986.

[17] Persson, P., Shrimpton, J. M., McCormick, S. D. \& Björnsson, B. Th., The presence of high-affinity, low-capacity estradiol-17 $\beta$ binding in rainbow trout scale indicates a possible endocrine route for the regulation of scale resorption. General and Comparative Endocrinology, 120, pp. 35-43, 2000.

[18] Singleton, D. W., Feng, Y., Yang, J., Puga, A., Lee, A. V. \& Khan, S. A., Gene expression profiling reveals novel regulation by bisphenol-A in estrogen receptor- $\alpha$-positive human cells. Environmental research, 100, pp. 86-92, 2006.

[19] Suzuki, N. \& Hattori, A., Bisphenol A suppresses osteoclastic and osteoblastic activities in the cultured scales of goldfish. Life Sciences, 73, pp. 2237-2247, 2003.

[20] Yoshikubo, H., Suzuki, N., Takemura, K., Hoso, M., Yashima, S., Iwamuro, S., Takagi, Y., Tabata, M. J. \& Hattori, A., Osteoblastic activity and estrogenic response in the regenerating scale of goldfish, a good model of osteogenesis. Life Sciences, 76, pp. 2699-2709, 2005.

[21] Persson, P., Sundell, K. \& Björnsson, B. Th., Estradiol-17 $\beta$-induced calcium uptake and resorption in juvenile rainbow trout, Oncorhynchus mykiss. Fish Physiology and Biochemistry, 13, pp. 379-386, 1994.

[22] Persson, P., Takagi, Y. \& Björnsson, B. Th., Tartrate resistant acid phosphatase as a marker for scale resorption in rainbow trout, Oncorhynchus mykiss: Effects of estradiol-17 $\beta$ treatment and refeeding. Fish Physiology and Biochemistry, 14, pp. 329-339, 1995.

[23] Guerreiro, P. M., Fuentes, J., Canario, A. V. M. \& Power, D. M., Calcium balance in sea bream (Sparus aurata): The effect of oestradiol-17 $\beta$. Journal of Endocrinology, 173, pp. 377-385, 2002.

[24] Peterson, C. H., Rice, S. D., Short, J. W., Esler, D., Bodkin, J. L., Ballachey, B. E. \& Irons, D. B., Long-term ecosystem response to the Exxon Valdez oil spill. Science, 302, pp. 2082-2086, 2003. 